OPEN ACCESS

Edited by:

Sebo Uithol,

Radboud University, Netherlands

Reviewed by:

Ricardo de Oliveira-Souza, Instituto D'Or de Pesquisa e Ensino

(IDOR), Brazil

Alfred Mele,

Florida State University, United States

${ }^{*}$ Correspondence:

Bauke M. de Jong

b.m.de.jong@umcg.nl

Specialty section:

This article was submitted to

Cognitive Science,

a section of the journal

Frontiers in Psychology

Received: 30 August 2018

Accepted: 07 February 2019

Published: 21 February 2019

Citation:

de Jong BM (2019) Free Will Emerges From a Multistage Process

of Target Assignment and Body-Scheme Recruitment for

Free Effector Selection.

Front. Psychol. 10:388.

doi: 10.3389/fpsyg.2019.00388

\section{Free Will Emerges From a Multistage Process of Target Assignment and Body-Scheme Recruitment for Free Effector Selection}

\author{
Bauke M. de Jong*
}

Department of Neurology, University Medical Center Groningen, University of Groningen, Groningen, Netherlands

Self-intended action implies an initial stage of assigning an external entity as target of action, with subsequent recruitment of body-scheme information serving the free selection of an appropriate effector system to achieve the action aim. This plurality underscores the concept that neuronal response freedom underlying the generation of such action is not necessarily restricted to a singular cerebral event at its initiation, but that such freedom is embedded in a series of successive processing steps. In this respect, action intention initially concerns the transition of a neutral object into a target of action, while the "will" to act further crystalizes with the recruitment of one's body scheme. The latter is a prerequisite for effector selection and indeed complements the emerging sense of agency. This temporal order of neuronal events fits a model of fronto-parietal interactions associated with volition. A concise behavioral experiment is additionally described, in which successively displayed balls represent either a recognizable object with distinct shape and color features, or a target of action. Instructions to write down the ball's characteristics were alternated by the command "action." When shifting from a neutral object to an action target, the ball was placed in one of three backgrounds: empty, an outdoor goal or indoor basket. In response to the action command, subjects reported intended actions such as kicking, seizing, throwing and heading, thus implicitly referring to the foot, hand, or head as chosen effector. For the latter the parietal cortex is strongly implicated, not only concerning predefined but also free selection. Although subjects were free to choose what to do with the ball, the environmental cues of the ball strongly influenced their choices. These results illustrate the temporal order in fronto-parietal processing associated with initial target assignment, instantly followed by the embodiment of will, i.e., the recruitment of body-scheme information for possible effector selection. Such multistage neuronal processing underlying free action selection underscores that the onset of brain signals prior to the perceived sense of free will is not a valid argument to reduce free will to an illusion.

Keywords: embodiment of will, body scheme, free effector selection, parietal cortex, volition 


\section{INTRODUCTION}

\section{Internal Versus External Action Cues}

The generation of self-intended action implies the cerebral organization of goal-directed movements not evoked by an explicit external cue. The prefrontal cortex has been strongly implicated in such function (Frith et al., 1991; Miller and Cohen, 2001; Koechlin and Hyafil, 2007), which is further underscored by symptoms that may arise from prefrontal impairment such as a reduced initiative to undertake internally motivated actions and enhanced responses to external stimuli (Lhermitte, 1983; De Renzi and Barbieri, 1992; Burgess and Shallice, 1996; Godefroy, 2003). Particularly involvement of the medial prefrontal cortex in free action selection has been emphasized (Lau et al., 2006; Mueller et al., 2007; Haggard, 2008; Rushworth, 2008; Zapparoli et al., 2017). This is in line with an influential model dissociating medial and lateral frontal cortex contributions, associated with internally and externally driven motor actions, respectively (Passingham et al., 2010). Regarding the latter, external cues may be seen as an intrinsic part of sensory information about the external world, which is predominantly channeled along indeed the lateral surface of the hemispheres, with strong parietalfrontal interconnections that extend from a dorsal visual pathway (Goodale and Milner, 1992).

On the other hand, self-intended action similarly implies interaction with one's environment, also in the temporal window preceding actual performance. In self-intended action, however, different from externally cued action, an initially neutral constituent of one's environment is assigned as a target of action, immediately followed by the embodiment of an action plan, i.e., recruitment of a body-scheme for selecting the appropriate motor outflow channels. In the present paper, the distinction of these two aspects of self-intended action (target assignment and free effector selection) is elaborated in order to argue that degrees of response freedom in a neuronal system underlying free action selection is based on a multistage process, of which the recording of brain activity before the perception of a free will to act, need not be in conflict with the concept of consciously intended action.

Without an overt external cue, the initiation of goal directed action within a dynamic environment is strongly influenced by internal reference parameters, enabling the assessment of new environmental circumstances in the context of possible action outcomes. In this, memorized experiences may set the level of reward expected from such possible action (Rolls, 2012). A default mode neuronal system, in which indeed particular medial frontal regions participate, has been postulated to facilitate the shift from an internal steadystate to externally directed action planning (Raichle, 2015). In addition, perceptual analysis of the meaning and/or emotional load of new environmental characteristics, channeled along a (ventral) occipito-temporal visual pathway (Goodale and Milner, 1992) to the orbitofrontal cortex, medial prefrontal cortex and basal ganglia may further reinforce the drive for action (Wager et al., 2005; Carlson et al., 2011; Grabenhorst and Rolls, 2011; Wunderlich et al., 2012; Schultz, 2015, 2016). In other words, perceptual analysis of environmental constituents, framed in the context pre-existing (memorized) information, may define a new target of action. Although it goes beyond the scope of this paper to further elaborate on the neuronal and neurochemical mechanisms implicated in primary sources of internal drives for action, functions and pathways of the monoaminergic transmitter systems might be considered in this respect, given their role in attention, vigilance and arousal (noradrenaline), depression, impulsivity and anxiety (serotonin), reward expectation and motivation (dopamine) (Robert and Benoit, 2008; Westbrook and Braver, 2016). In a psychological context, such an internal driving force has been linked to the concept of conation, i.e., mental energy also required for sustained performance (Reitan and Wolfson, 2000).

The afore described neuronal mechanisms may thus well explain the internal generation of goal directed action, without the necessity of introducing a self-conscious actor as the initiator of voluntary action. On the other hand, the perception of a "free will" to initiate action or refrain from it, as well as the sense of agency, i.e., the feeling of being in control of one's actions, is an undeniable first-person experience. Although it should be kept in mind that responses of a human subject need to be epistemologically distinguished from responses of neuronal tissue (de Jong, 1989; Bennett et al., 2007), a first challenge to reconcile these different levels of scientific assessment is to find associations between reported perception and distinct cerebral activity underlying self-intended action. The experiment of Libet addressed this issue and revealed that the onset of intentionassociated cerebral activity preceded the perception of one's free will to push a button by means of a finger movement, i.e., the awareness of a non-cued intention to move (Libet et al., 1983; Haggard, 2008). This has been used as an argument that the feeling of voluntary control may be characterized as an illusion (Rolls, 2012): apparently, the sense of agency has no causal relation with the actual initiation of action because it follows such initiation. On the other hand, recent experimental data indicate that neuronal processing underlying free selection involves multiple stages of goal-directed action, both parallel and in sequential order (Cisek and Kalaska, 2010; Cui and Andersen, 2011; Rushworth et al., 2012). This implies that unconscious and conscious decision making may be complementary to and not at odds with each other. Particularly the parietal contribution to decision making provides conceptual arguments for associations between free selection at the level of neuronal processing and the perception of free will and sense of agency at subject level (Sirigu et al., 1999, 2004; Farrer and Frith, 2002; Nahab et al., 2011; Desmurget and Sirigu, 2012).

Regarding the Libet experiment one might oppose that the advocated model of successive stages involved in the initiation of internally generated action, perceived as self-intended, does not directly apply to Libet's design. Indeed, the latter did not address a natural condition in which participants express spontaneous self-intended actions in interaction with their environment; participants were instructed to make a free choice in time when to push a button. This implies that the task instruction is kept in memory, while the button and a clock are the external objects on which ongoing attention is focussed. In this 
respect, the Libet experiment is consistent with the postulated multistage model of (free) action intention, in such a way that the initial stage concerns an (unconscious) actualization of the instruction kept in memory ("push the button") while subsequently, the button becomes an overt target again, with the recruitment of one's body scheme for (fixed) selection of the finger used to push. This second stage is proposed to be associated with the conscious experience of the self-intended act to move, while a final stage before actual motor execution might address final action consent or veto (internal no-go), mediated by prefrontal interconnections (Chikazoe, 2010; de Jong, 2011; Cieslik et al., 2015).

\section{Parietal Motor Functions and Sense of Agency}

As described in the previous paragraphs, next to the shift of a neutral environmental object into a target of action, a representation of body-scheme is recruited to accommodate free effector selection. At this stage, the parietal cortex is crucially involved. This parietal involvement concerns multiple levels of complexity, ranging from the somatotopic representation of body parts and sensorimotor transformations to the perceived sense of agency. Mapping the spatial relationships between body parts to construct a body scheme (Maravita et al., 2003; Longo et al., 2010; Sereno and Huang, 2014), channeling sensorimotor transformations (Binkofski et al., 1999; de Jong et al., 2001; Freund, 2001; Filimon, 2010; Heed et al., 2015) and the initiation of invariantly instructed motor actions (Andersen, 1995; de Jong et al., 1999; Medendorp et al., 2008; Gallivan et al., 2011) have become well-established parietal functions. More recently, involvement of parietal-premotor circuitry in free selection has highlighted that decision making may already take place at early stages of visuomotor planning, without prefrontal involvement (Platt and Glimcher, 1999; Shadlen and Newsome, 2001; Cisek, 2007; Pesaran et al., 2008; Cisek and Kalaska, 2010). Apparently, the brain employs a strategy of initiating multiple potential motor plans of which one is further elaborated, particularly in conditions of a dynamic environment. This does not only hold for actions that require a selection between distinct environmental targets, but also concerns the variance how to execute a given motor task. The latter is demonstrated by the increased activations in both dorsal premotor and inferior parietal cortices related to free finger selection, contrasted to the invariant condition of fixed finger selection (Beudel and de Jong, 2009).

Beyond its contribution to early-stage decision making, the parietal cortex exhibits unique fields at which direct cortical stimulation may evoke the perceived urge to move a specific body part (Desmurget et al., 2009). The coinciding parietal involvement in both initiating internally generated action and the perception of self-intended action implies that (i) parietal circuitry is characterized by distinct degrees of freedom in neuronal response patterns associated with free motor selection and (ii) this neuronal circuitry can be stimulated in such a way that the perception of self-intended movement arises. Finally, the parietal cortex, in concert with the cerebellum, plays a distinct role in predicting the sensory consequences of goal-directed movement, which is an essential component in motor preparation (McCloskey, 1981; Blakemore and Sirigu, 2003; Poulet and Hedwig, 2007; Beudel et al., 2011; Sokolov et al., 2017). But even more, matching such predicted (feedforward) and actual (feedback) information, dissociated from externally evoked sensation, appears to be a neuronal mechanism associated with the emerging sense of agency, i.e., attributing the effect of a motor action to oneself (Blakemore et al., 1998; Blakemore and Sirigu, 2003; Haggard, 2017). Misalignment of actual and predicted action consequences may result in a reduced sense of agency and even in the illusion of alien action control (Blakemore et al., 2002; Voss et al., 2010). The notion of anticipated sensation may further provide theoretical support for a model of a prospective perception of free will (Metcalfe and Greene, 2007; de Jong, 2011; Chambon et al., 2013).

To summarize, two successive stages were postulated concerning the initiation of internally generated action, and further specified in the preceding paragraphs. The first stage of assigning an environmental "object" to become a target of action, plausibly unconscious, is followed by a stage of organizing the means how to perform such action, i.e., how to give "hands and feet" to an action plan. At this second stage, recruitment of a body-scheme is considered to be a prerequisite for the free selection of an appropriate effector system. The parietal involvement in such effector selection, in the context of the above treated range of parietal functions, provides a strong argument to infer that at this stage, an association can be made between neuronal activity underlying free self-intended action and the perception of a "free will" to initiate such action. While the onset of cerebral activity related to self-intended action thus defines the initial stage, the "second-stage" neuronal activity, which is particularly implicated in free effector selection, and logically associated with the emerging sense of free self-intended action, remains causally involved in the multi-stage process of free selections. In other words, the onset of brain signals prior to the perceived sense of a free will is not a valid argument to reduce free will to an illusion.

\section{EXPERIMENTAL ILLUSTRATION}

In the following paragraphs, a concise proof-of-principle experiment will be briefly described, illustrating the serial order of segregating (i) the shift from the neutral description of a displayed ball into a target of action, and (ii) the recruitment of body-scheme information for free effector selection. Regarding the latter, the displayed surrounding of the presented ball may implicitly influence the (free) selection of e.g., an arm or a leg to employ performance with the ball.

\section{Methods of the Experiment}

Ten healthy male subjects (one left-hand preference) with a mean age (SD) of 35.3 years (10.7) and ten healthy female subjects aged 35.4 years (13.4), of which two had left-hand preference, participated in the study. Aside from a personal history in 


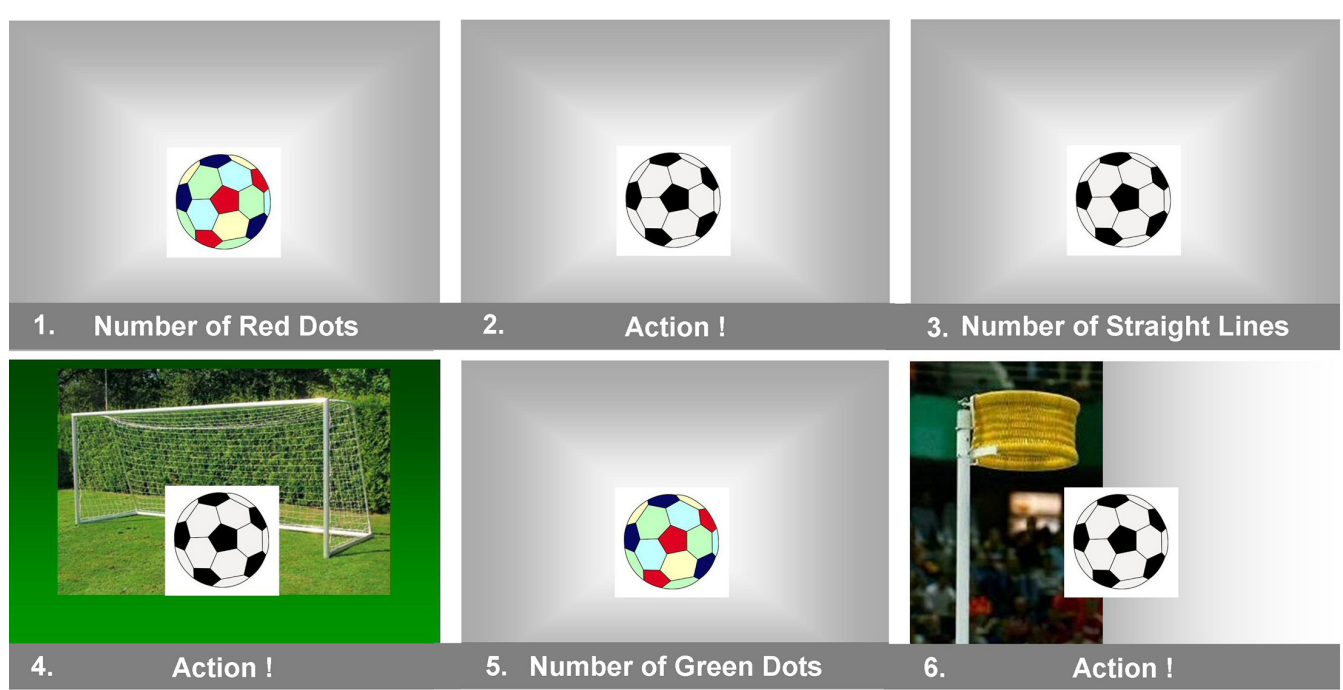

FIGURE 1 | Displays of the ball as neutral object or a target. A series of the 6 displays of the ball is presented in the order 1-6. Subjects were asked to give a specific description of features on the ball's surface when images 1, 3, and 5 were presented. Images 2, 4, and 6 labeled the ball as a target for virtual (free chosen) action. In the actual PowerPoint presentation used for the experiment, the instructions written at the bottom side of the images 1 , 3 and 5 were a bit longer, e.g., image 1 was labeled with "write down the number of red dots you see."

sports, no further subject data were filed. According to national regulation in Netherlands, the absence of filing personal details and the fact that the experiment did not inflict a burden on the participants, it was not required to obtain approval from the local Ethics Committee. In line with this strategy to refrain from filing personal data, only oral informed consent was obtained. Participants viewed a computer monitor displaying a power point presentation with a series of 6 pictures, showing a ball that remained at the same position in the center of the successive images. Subjects were informed that various pictures of a ball would be presented, each accompanied by either a question concerning specific features of the ball or the label "action," written at the bottom of each display. They had to respond by either writing the answer concerning the ball's characteristics or noting the virtual performance that came to their mind in response to the "action" command. No examples were given, subjects were told that the command for action meant that they had to write down "what they would do." It is important to understand that, although both conditions in this design include external commands, the "action command" (i) implied the shift from the ball as a neutral object of description into a target of action, and (ii) aimed to test that the obtained answer indeed reflects the recruitment of an effector system, while the actual effector is selected by the participant's free choice.

The series of 6 trials (Figure 1) started with a picture of the ball with its surface marked by adjacent pentagon-shaped dots of various colors, placed on an empty gray background. Subjects had to count the red dots. Next, the ball appeared in black-and-white on the same empty background labeled with the "action" command. The third picture was unchanged, however, subjects had to note the number of straight lines on de ball delineating two adjacent pentagon-shaped dots. Next, the same ball was depicted with an outdoor goal in the background, accompanied by the "action" command at the bottom. The fifth picture was similar to the first, only now subjects had to count the green dots. The final picture with the "action" request framed the black-and-white colored ball with an indoor korfball basket.

\section{Experimental Results}

All 20 subjects provided answers as requested. The descriptions of the ball's features (questions 1, 3, and 5) were generally correct.

TABLE 1 | Free self-intended virtual actions.

\begin{tabular}{|c|c|c|c|c|c|}
\hline \multirow{3}{*}{$\begin{array}{l}\text { "Action" } \\
\text { Response } \\
\text { Given by } \\
\text { particiapants }\end{array}$} & \multicolumn{3}{|c|}{ Distribution of Actions } & \multicolumn{2}{|c|}{ Implicit Effector } \\
\hline & \multicolumn{3}{|c|}{ Background scenery of the bal: } & & \\
\hline & $\begin{array}{c}\text { No } \\
\text { context }\end{array}$ & $\begin{array}{c}\text { Outdoor } \\
\text { goal }\end{array}$ & $\begin{array}{l}\text { Indoor } \\
\text { basket }\end{array}$ & \multicolumn{2}{|c|}{ Sum } \\
\hline \# Kicking & 15 & 16 & - & Foot & 31 \\
\hline \# Seizing & 3 (2F, 1Fa) & - & - & Hand & \\
\hline \# Catching & - & $1(\mathrm{M})$ & - & Hand & \\
\hline \# Throwing & - & $1(\mathrm{Fa})$ & 19 & Hand, sum: & 24 \\
\hline \# Heading & - & $1(\mathrm{M})$ & - & Head & 1 \\
\hline $\begin{array}{l}\text { \# Counting } \\
\text { black dots }\end{array}$ & $2(1 \mathrm{~F}, 1 \mathrm{Mb})$ & $1(\mathrm{Mb})$ & $1(M b)$ & None & 4 \\
\hline Sum & 20 & 20 & 20 & & 60 \\
\hline
\end{tabular}

Table 1 lists the answers that were obtained from the 20 subjects in response to the displays of the ball when accompanied by the request for virtual "action." Before the experiment, subjects were instructed to write down the virtual performance that came to their mind at the appearance of each of the three "action" images. $M$, male $(n=10) ; F$, female $(n=10)$; (a) and (b) indicate two distict subjects. 
The 60 responses to the "action" commands that accompanied displays 2, 4, and 6 are listed in Table 1. Fifty-six responses concerned kicking, seizing, throwing or heading while 4 of 60 responses concerned counting of dots. The background clearly influenced the choice that was made although the selection had remained entirely free. With the basket in the background 19 of 20 subjects responded by the intention to throw the ball. A few subjects commented that, in the empty background, the blackand-white colored ball looked like a football, which was a reason to indicate kicking it away.

\section{COMMENTS ON THE EXPERIMENT}

The answers given with regard to the specific features of the ball were based on overt perception of these characteristics, which fits the classical involvement of predominantly the ventral visual pathway (Goodale and Milner, 1992). This involvement may include both bottom-up and top-down information processing (Zeki and Shipp, 1988; Roe et al., 2012). Although the "action" trails were dominated by virtual performance, more covert perception of the ball's background clearly influenced the chosen virtual action. In the initial phase of action initiation, with the perceptual shift from the ball as a subject of visual assessment into a target of action, its visual surrounding thus unconsciously added further qualification of the target. In the next stage, to achieve the intended action, a hand, foot, or the head was implicitly chosen for virtually performing kicking, seizing, throwing, or heading. This embodiment of an action plan required the recruitment of one's body scheme. In other words, action aimed at the ball, an external object, was now linked to a specific body part, which implies a link to oneself. It is therefore at this stage, with the above argued involvement of particularly parietal functions, that free effector selection may be logically associated with the emerging perception of a free will of making such selection.

The covert influence of the ball's visual environment on free effector selection points at interactions between the ventral and dorsal visual pathways. Such interactions may be based on direct temporal-parietal interconnection or mediated along temporalprefrontal pathways toward parietal circuitry (Goodale, 2011; van Polanen and Davare, 2015; Milner, 2017). The presented experiment with a single object (the ball) placed in various conditions, differed from the more natural circumstance with multiple environmental objects, of which one is assigned as

\section{REFERENCES}

Andersen, R. A. (1995). Encoding of intention and spatial location in the posterior parietal lobe. Cereb. Cortex 5, 457-469. doi: 10.1093/cercor/5.5.457

Bennett, M., Dennett, D., Hacker, P., and Searle, J. (2007). Neuroscience and Philosophy. New York, NY: Columbia Press.

Beudel, M., and de Jong, B. M. (2009). Overlap and segregation in predorsal premotor cortex activations related to free selection of self-referenced and target-based finger movements. Cereb. Cortex 19, 2361-2371. doi: 10.1093/ cercor/bhn254

Beudel, M., Zijlstra, S., Mulder, T., Zijdewind, I., and de Jong, B. M. (2011). Secondary sensory area SII is crucially involved in the preparation of familiar a target of action. Although the experimental and natural circumstances both include the shift from a neutral object into a target of action, there was no selection between objects in the experiment. Unconscious object selection in natural circumstances may be stronger embedded in a ventral visual pathway fuelling top-down prefrontal-parietal interactions (Grabenhorst and Rolls, 2011; Wunderlich et al., 2012), compared to the more variable temporal-parietal interaction assumed in this experiment (van Polanen and Davare, 2015). Not only the ball's background influenced the choice for action. Without background features, the surface pattern of the ball may have suggested a football, explaining the preference for kicking. In response to e.g., a displayed bowling ball, kicking would have been an unlikely choice.

\section{CONCLUSION}

At the initiation of free self-intended action, a succession of multiple neuronal processing steps may be discerned. An initial stage of unconsciously assigning a neutral object to become a target of action is followed by a second stage of body-scheme recruitment, enabling the selection of an effector to achieve the intended action. While initially, intention is aimed at the external target, the embodiment of an action plan represents the subsequent linkage between the intended action and a specific body part, thus linking the action to oneself. At this stage, when particularly parietal functions are involved, free effector selection may be logically associated with the emerging sense of agency and perception of a free will in action control. This postulated multistage neuronal processing underlying free action selection underscores that the onset of brain signals prior to the perceived sense of free will is not a valid argument to reduce free will to an illusion. A multistage model, as presented in this paper, may further lay ground for novel experimental designs to explore various steps in the association between internally generated action and the perception of such self-intended action, aimed at providing a more accurate, and undisputed definition of free will.

\section{AUTHOR CONTRIBUTIONS}

The author confirms being the sole contributor of this work and has approved it for publication.

movements compared to movements never made before. Hum. Brain Mapp. 32, 564-579. doi: 10.1002/hbm.21044

Binkofski, F., Buccino, G., Posse, S., Seitz, R. J., Rizzolatti, G., and Freund, H. (1999). A fronto-parietal circuit for object manipulation in man: evidence from an fMRI-study. Eur. J. Neurosci. 11, 3276-3286. doi: 10.1046/j.1460-9568.1999. 00753.x

Blakemore, S. J., and Sirigu, A. (2003). Action prediction in the cerebellum and in the parietal lobe. Exp. Brain Res. 153, 239-245. doi: 10.1007/s00221-003$1597-z$

Blakemore, S. J., Wolpert, D. M., and Frith, C. D. (1998). Central cancellation of self-produced tickle sensation. Nat. Neurosci. 1, 635-640. doi: 10.1038/ 2870 
Blakemore, S. J., Wolpert, D. M., and Frith, C. D. (2002). Abnormalities in the awareness of action. Trends Cogn. Sci. 6, 237-242. doi: 10.1016/S1364-6613(02) 01907-1

Burgess, P. W., and Shallice, T. (1996). Response suppression, initiation and strategy use following frontal lobe lesions. Neuropsychologia 34, 263-272. doi: 10.1016/0028-3932(95)00104-2

Carlson, J. M., Foti, D., Mujica-Parodi, L. R., Harmon-Jones, E., and Hajcak, G. (2011). Ventral striatal and medial prefrontal BOLD activation is correlated with reward-related electrocortical activity: a combined ERP and fMRI study. Neuroimage 57, 1608-1616. doi: 10.1016/j.neuroimage.2011. 05.037

Chambon, V., Wenke, D., Fleming, S. M., Prinz, W., and Haggard, P. (2013). An online neural substrate for sense of agency. Cereb. Cortex 23, 1031-1037. doi: 10.1093/cercor/bhs059

Chikazoe, J. (2010). Localizing performance of go/no-go tasks to prefrontal cortical subregions. Curr. Opin. Psychiatry 23, 267-272. doi: 10.1097/YCO. 0b013e3283387a9f

Cieslik, E. C., Mueller, V. I., Eickhoff, C. R., Langner, R., and Eickhoff, S. B. (2015). Three key regions for supervisory attentional control: evidence from neuroimaging meta-analyses. Neurosci. Biobehav. Rev. 48, 22-34. doi: 10.1016/ j.neubiorev.2014.11.003

Cisek, P. (2007). Cortical mechanisms of action selection: the affordance competition hypothesis. Philos. Trans. R. Soc. Lond. B Biol. Sci. 362, 1585-1599. doi: 10.1098/rstb.2007.2054

Cisek, P., and Kalaska, J. F. (2010). Neural mechanisms for interacting with a world full of action choices. Annu. Rev. Neurosci. 33, 269-298. doi: 10.1146/annurev. neuro.051508.135409

Cui, H., and Andersen, R. A. (2011). Different representations of potential and selected motor plans by distinct parietal areas. J. Neurosci. 31, 18130-18136. doi: 10.1523/JNEUROSCI.6247-10.2011

de Jong, B. M. (1989). Inside world, outside world: epistemology on the conscious action of the central nervous system. Methodol. Sci. 22, 230-236.

de Jong, B. M. (2011). Neurology of widely embedded free will. Cortex 47, 1160-1165. doi: 10.1016/j.cortex.2011.06.011

de Jong, B. M., van der Graaf, F. H., and Paans, A. M. J. (2001). Brain activation related to the representations of external space and body scheme in visuomotor control. Neuroimage 14, 1128-1135. doi: 10.1006/nimg.2001. 0911

de Jong, B. M., Willemsen, A. T. M., and Paans, A. M. J. (1999). Brain activation related to the change between bimanual motor programs. NeuroImage 9, 290-297. doi: 10.1006/nimg.1998.0410

De Renzi, E., and Barbieri, C. (1992). The incidence of the grasp reflex following hemispheric lesion and its relation to frontal damage. Brain 115, 293-313. doi: 10.1093/brain/115.1.293

Desmurget, M., Reilly, K. T., Richard, N., Szathmari, A., Mottolese, C., and Sirigu, A. (2009). Movement intention after parietal cortex stimulation in humans. Science 324, 811-813. doi: 10.1126/science.1169896

Desmurget, M., and Sirigu, A. (2012). Conscious motor intention emerges in the inferior parietal lobule. Curr. Opin. Neurobiol. 22, 1004-1011. doi: 10.1016/j. conb.2012.06.006

Farrer, C., and Frith, C. D. (2002). Experiencing oneself vs another person as being the cause of an action: the neural correlates of the experience of agency. Neuroimage 15, 596-603. doi: 10.1006/nimg.2001.1009

Filimon, F. (2010). Human cortical control of hand movements: parietofrontal networks for reaching, grasping, and pointing. Neuroscientist 16, 388-407. doi: $10.1177 / 1073858410375468$

Freund, H. J. (2001). The parietal lobe as a sensorimotor interface: a perspective from clinical and neuroimaging data. Neuroimage 14(1 Pt 2), S142-S146. doi: 10.1006/nimg.2001.0863

Frith, C. D., Friston, K. J., Liddle, P. F., and Frackowiak, R. S. J. (1991). Willed action and the prefrontal cortex in man: a study with PET. Proc. Biol. Sci. 244, 241-246. doi: 10.1098/rspb.1991.0077

Gallivan, J. P., McLean, D. A., Smith, F. W., and Culham, J. C. (2011). Decoding effector-dependent and effector-independent movement intentions from human parieto-frontal brain activity. J. Neurosci. 31, 17149-17168. doi: 10.1523/JNEUROSCI.1058-11.2011

Godefroy, O. (2003). Frontal syndrome and disorders of executive functions. J. Neurol. 250, 1-6. doi: 10.1007/s00415-003-0918-2
Goodale, M. A. (2011). Transforming vision into action. Vision Res. 51, 1567-1587. doi: 10.1016/j.visres.2010.07.027

Goodale, M. A., and Milner, A. D. (1992). Separate visual pathways for perception and action. Trends Neurosci. 15, 20-25. doi: 10.1016/0166-2236(92) 90344-8

Grabenhorst, F., and Rolls, E. T. (2011). Value, pleasure and choice in the ventral prefrontal cortex. Trends Cogn. Sci. 15, 56-67. doi: 10.1016/j.tics.2010. 12.004

Haggard, P. (2008). Human volition: towards a neuroscience of will. Nat. Rev. Neurosci. 9, 934-946. doi: 10.1038/nrn2497

Haggard, P. (2017). Sense of agency in the human brain. Nat. Rev. Neurosci. 18, 196-207. doi: 10.1038/nrn.2017.14

Heed, T., Buchholz, V. N., Engel, A. K., and Röder, B. (2015). Tactile remapping: from coordinate transformation to integration in sensorimotor processing. Trends Cogn. Sci. 19, 251-258. doi: 10.1016/j.tics.2015.03.001

Koechlin, E., and Hyafil, A. (2007). Anterior prefrontal function and the limits of human decision-making. Science 318, 594-598. doi: 10.1126/science. 1142995

Lau, H. C., Rogers, R. D., and Passingham, R. E. (2006). Dissociating response selection and conflict in the medial frontal surface. Neuroimage 29, 446-451. doi: 10.1016/j.neuroimage.2005.07.050

Lhermitte, F. (1983). 'Utilization behaviour' and its relation to lesions of the frontal lobes. Brain 106, 237-255. doi: 10.1093/brain/106.2.237

Libet, B., Gleason, C. A., Wright, E. W., and Pearl, D. K. (1983). Time of conscious intention to act in relation to onset of cerebral activity (readiness-potential). The unconscious initiation of a freely voluntary act. Brain 106, 623-642. doi: 10.1093/brain/106.3.623

Longo, M. R., Azañón, E., and Haggard, P. (2010). More than skin deep: body representation beyond primary somatosensory cortex. Neuropsychologia 48, 655-668. doi: 10.1016/j.neuropsychologia.2009.08.022

Maravita, A., Spence, C., and Driver, J. (2003). Multisensory integration and the body schema: close to hand and within reach. Curr. Biol. 13, R531-R539. doi: 10.1016/S0960-9822(03)00449-4

McCloskey, D. I. (1981). “Corollary Discharges: motor commands and perception," in Handbook of Physiology, Section 1: The Nervous System: Motor Control, Vol. 2, eds V. B. Brooks, J. M. Brookhart, and V. B. Mountcastle (Bethesda, MD: American Physiological Society), 1415-1447.

Medendorp, W. P., Beurze, S. M., Van Pelt, S., and Van Der Werf, J. (2008). Behavioral and cortical mechanisms for spatial coding and action planning. Cortex 44, 587-597. doi: 10.1016/j.cortex.2007.06.001

Metcalfe, J., and Greene, M. J. (2007). Metacognition of agency. J. Exp. Psychol. Gen. 136, 184-199. doi: 10.1037/0096-3445.136.2.184

Miller, E. K., and Cohen, J. D. (2001). An integrative theory of prefrontal cortex function. Annu. Rev. Neurosci. 24, 167-202. doi: 10.1146/annurev.neuro.24. 1.167

Milner, A. D. (2017). How do the two visual streams interact with each other? Exp. Brain Res. 235, 1297-1308. doi: 10.1007/s00221-017-4917-4

Mueller, V. A., Brass, M., Waszak, F., and Prinz, W. (2007). The role of the preSMA and the rostral cingulate zone in internally selected actions. Neuroimage 37, 1354-1361. doi: 10.1016/j.neuroimage.2007.06.018

Nahab, F. B., Kundu, P., Gallea, C., Kakareka, J., Pursley, R., Pohida, T., et al. (2011). The neural processes underlying self-agency. Cereb. Cortex 21, 48-55. doi: 10.1093/cercor/bhq059

Passingham, R. E., Bengtsson, S. L., and Lau, H. C. (2010). Medial frontal cortex: from self-generated action to reflection on one's own performance. Trends Cogn. Sci. 14, 16-21. doi: 10.1016/j.tics.2009.11.001

Pesaran, B., Nelson, M. J., and Andersen, R. A. (2008). Free choice activates a decision circuit between frontal and parietal cortex. Nature 453, 406-409. doi: 10.1038 /nature 06849

Platt, M. L., and Glimcher, P. W. (1999). Neural correlates of decision variables in parietal cortex. Nature 400, 233-238. doi: 10.1038/22268

Poulet, J. F., and Hedwig, B. (2007). New insights into corollary discharges mediated by identified neural pathways. Trends Neurosci. 30, 14-21. doi: 10. 1016/j.tins.2006.11.005

Raichle, M. E. (2015). The brain's default mode network. Annu. Rev. Neurosci. 38, 433-447. doi: 10.1146/annurev-neuro-071013-014030

Reitan, R. M., and Wolfson, D. (2000). Conation: a neglected aspect of neuropsychological functioning. Arch. Clin. Neuropsychol. 15, 443-453. 
Robert, P. H., and Benoit, M. (2008). "Neurochemistry of cognition: serotonergic and adrenergic mechanisms," in Handbook of Clinical Neurology, Vol. 88, eds G. Goldenberg and B. L. Miller (Amsterdam: Elsevier), 31-40.

Roe, A. W., Chelazzi, L., Connor, C. E., Conway, B. R., Fujita, I., Gallant, J. L., et al. (2012). Toward a unified theory of visual area V4. Neuron 74, 12-29. doi: 10.1016/j.neuron.2012.03.011

Rolls, E. T. (2012). Willed action, free will, and the stochastic neurodynamics of decision-making. Front. Integr. Neurosci. 6:68. doi: 10.3389/fnint.2012.00068

Rushworth, M. F. (2008). Intention, choice, and the medial frontal cortex. Ann. N. Y. Acad. Sci. 1124, 181-207. doi: 10.1196/annals.1440.014

Rushworth, M. F., Kolling, N., Sallet, J., and Mars, R. B. (2012). Valuation and decision-making in frontal cortex: one or many serial or parallel systems? Curr. Opin. Neurobiol. 22, 946-955. doi: 10.1016/j.conb.2012.04.011

Schultz, W. (2015). Neuronal reward and decision signals: from theories to data. Physiol. Rev. 95, 853-951. doi: 10.1152/physrev.00023.2014

Schultz, W. (2016). Reward functions of the basal ganglia. J. Neural Transm. 123, 679-693. doi: 10.1007/s00702-016-1510-0

Sereno, M. I., and Huang, R. S. (2014). Multisensory maps in parietal cortex. Curr. Opin. Neurobiol. 24, 39-46. doi: 10.1016/j.conb.2013.08.014

Shadlen, M. N., and Newsome, W. T. (2001). Neural basis of a perceptual decision in the parietal cortex (area LIP) of the rhesus monkey. J. Neurophysiol. 86, 1916-1936. doi: 10.1152/jn.2001.86.4.1916

Sirigu, A., Daprati, E., Ciancia, S., Giraux, P., Nighoghossian, N., Posada, A., et al. (2004). Altered awareness of voluntary action after damage to the parietal cortex. Nat. Neurosci. 7, 80-84. doi: 10.1038/nn1160

Sirigu, A., Daprati, E., Pradat-Diehl, P., Franck, N., and Jeannerod, M. (1999). Perception of self-generated movement following left parietal lesion. Brain 122, 1867-1874. doi: 10.1093/brain/122.10.1867

Sokolov, A. A., Miall, R. C., and Ivry, R. B. (2017). The cerebellum: adaptive prediction for movement and cognition. Trends Cogn. Sci. 21, 313-332. doi: 10.1016/j.tics.2017.02.005 van Polanen, V., and Davare, M. (2015). Interactions between dorsal and ventral streams for controlling skilled grasp. Neuropsychologia 79(Pt B), 186-191. doi: 10.1016/j.neuropsychologia.2015.07.010

Voss, M., Moore, J., Hauser, M., Gallinat, J., Heinz, A., and Haggard, P. (2010). Altered awareness of action in schizophrenia: a specific deficit in predicting action consequences. Brain 133, 3104-3112. doi: 10.1093/brain/ awq152

Wager, T. D., Jonides, J., Smith, E. E., and Nichols, T. E. (2005). Toward a taxonomy of attention shifting: individual differences in fMRI during multiple shift types. Cogn. Affect. Behav. Neurosci. 5, 127-143. doi: 10.3758/CABN.5.2.127

Westbrook, A., and Braver, T. S. (2016). Dopamine does double duty in motivating cognitive effort. Neuron 89, 695-710. doi: 10.1016/j.neuron.2015.12.029

Wunderlich, K., Dayan, P., and Dolan, R. J. (2012). Mapping value based planning and extensively trained choice in the human brain. Nat. Neurosci. 15, 786-791. doi: 10.1038/nn.3068

Zapparoli, L., Seghezzi, S., and Paulesu, E. (2017). The what, the when, and the whether of intentional action in the brain: a meta-analytical review. Front. Hum. Neurosci. 11:238. doi: 10.3389/fnhum.2017.00238

Zeki, S., and Shipp, S. (1988). The functional logic of cortical connections. Nature 335, 311-317. doi: 10.1038/335311a0

Conflict of Interest Statement: The author declares that the research was conducted in the absence of any commercial or financial relationships that could be construed as a potential conflict of interest.

Copyright (c) 2019 de Jong. This is an open-access article distributed under the terms of the Creative Commons Attribution License (CC BY). The use, distribution or reproduction in other forums is permitted, provided the original author(s) and the copyright owner(s) are credited and that the original publication in this journal is cited, in accordance with accepted academic practice. No use, distribution or reproduction is permitted which does not comply with these terms. 